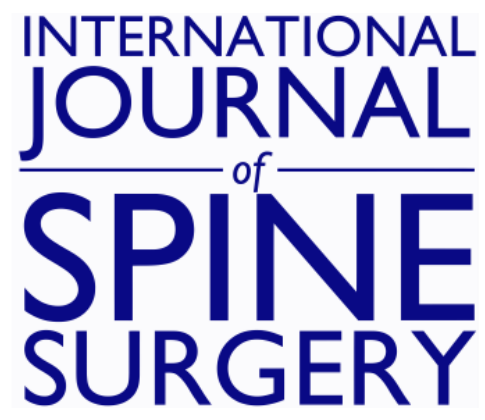

\title{
Biomechanical Characteristics of an Integrated Lumbar Interbody Fusion Device
}

Leonard I. Voronov, Georgios Vastardis, Julia Zelenakova, Gerard Carandang, Robert M. Havey, Erik I. Waldorff, Michael R. Zindrick and Avinash G. Patwardhan

Int J Spine Surg 2014, 8 ()

doi: https://doi.org/10.14444/1001

http://ijssurgery.com/content/8/1

This information is current as of April 26, 2023.

Email Alerts Receive free email-alerts when new articles cite this article. Sign up at:

http://ijssurgery.com/alerts

The International Journal of Spine Surgery

2397 Waterbury Circle, Suite 1,

Aurora, IL 60504, Phone: +1-630-375-1432 


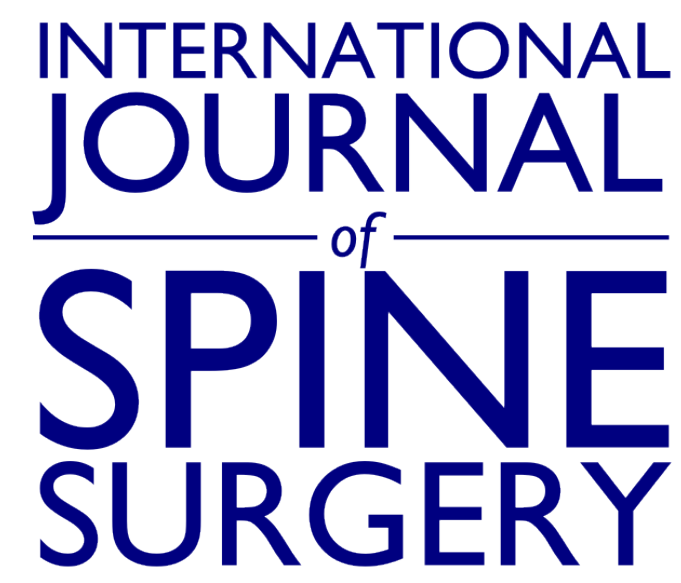

This article generously published free of charge by the International Society for the Advancement of Spine Surgery.

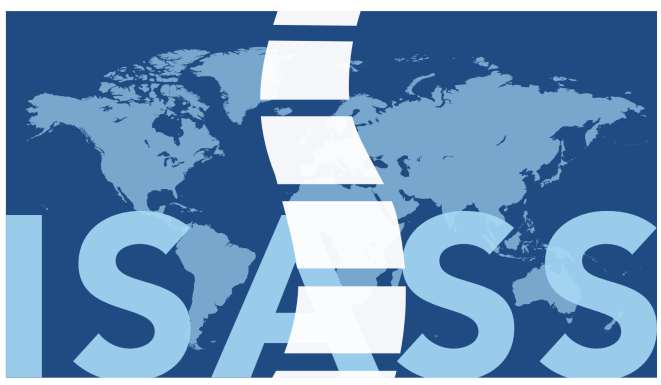

INTERNATIONAL SOCIETY for the ADVANCEMENT of SPINE SURGERY 


\section{Biomechanical Characteristics of an Integrated Lumbar Interbody Fusion Device}

Leonard I. Voronov, MD, PhD ${ }^{1,2}$; Georgios Vastardis, $M D^{1,2}$; Julia Zelenakova, $M S^{2}$; Gerard Carandang, $M S^{2}$; Robert M. Havey, BS ${ }^{1,2}$; Erik I. Waldorff, PhD ${ }^{3}$; Michael R. Zindrick, $M D^{1}$; Avinash G. Patwardhan, Ph.D. ${ }^{1,2}$

${ }^{1}$ Department of Orthopaedic Surgery and Rehabilitation, Loyola University Medical Center, Maywood, Illinois. ${ }^{2}$ Musculoskeletal Biomechanics Laboratory, Department of Veterans Affairs, Edward Hines Jr. VA Hospital, Hines, Illinois. ${ }^{3}$ Orthofix, Lewisville, Texas

\section{Abstract}

\section{Introduction}

We hypothesized that an Integrated Lumbar Interbody Fusion Device (PILLAR SA, Orthofix, Lewisville, TX) will function biomechanically similar to a traditional anterior interbody spacer (PILLAR AL, Orthofix, Lewisville, TX) plus posterior instrumentation (FIREBIRD, Orthofix, Lewisville, TX). Purpose of this study was to determine if an Integrated Interbody Fusion Device (PILLAR SA) can stabilize single motion segments as well as an anterior interbody spacer (PILLAR AL) + pedicle screw construct (FIREBIRD).

\section{Methods}

Eight cadaveric lumbar spines (age: $43.9 \pm 4.3$ years) were used. Each specimen's range of motion was tested in flexion-extension (FE), lateral bending (LB), and axial rotation (AR) under intact condition, after L4-L5 PILLAR SA with intervertebral screws and after L4-L5 $360^{\circ}$ fusion (PILLAR AL+Pedicle Screws and rods (FIREBIRD). Each specimen was tested in flexion $(8 \mathrm{Nm})$ and extension $(6 \mathrm{Nm})$ without preload $(0 \mathrm{~N})$ and under $400 \mathrm{~N}$ of preload, in lateral bending $( \pm 6 \mathrm{Nm})$ and axial rotation $( \pm 5 \mathrm{Nm})$ without preload.

\section{Results}

Integrated fusion using the PILLAR SA device demonstrated statistically significant reductions in range of motion of the L4-L5 motion segment as compared to the intact condition for each test direction. PILLAR SA reduced ROM from $8.9 \pm 1.9$ to $2.9 \pm 1.1^{\circ}$ in FE with $400 \mathrm{~N}$ follower preload (67.4\%), $8.0 \pm 1.7$ to $2.5 \pm 1.1^{\circ}$ in $\mathrm{LB}$, and $2.2 \pm 1.2$ to $0.7 \pm 0.3^{\circ}$ in AR. A comparison between the PILLAR SA integrated fusion device versus $360^{\circ}$ fusion construct with spacer and bilateral pedicle screws was statistically significant in FE and $\mathrm{LB}$. The $360^{\circ}$ fusion yielded motion of $1.0 \pm 0.5^{\circ}$ in FE, $1.0 \pm 0.8^{\circ}$ in $\mathrm{LB}$ (p0.05). 


\section{Conclusions}

The PILLAR SA resulted in motions of less than $3^{\circ}$ in all modes of motion and was not as motion restricting as the traditional $360^{\circ}$ using bilateral pedicle screws. The residual segmental motions compare very favorably with published biomechanical studies of other interbody integrated fusion devices.

keywords: Integrated Lumbar Interbody Fusion, lumbar spine, biomechanics

Volume 8 Article 1 doi: 10.14444/1001

\section{Introduction}

Lumbar interbody fusion is an often performed and well described procedure. The most commonly utilized fusion construct involves anterior and posterior fixation ( $360^{\circ}$ fusion) utilizing an interbody graft/spacer with posterior pedicle screws and rods which substantially increases the stability of ALIF construct ${ }^{1,2,3,4,5,6,7,8}$ and is associated with a significantly improved fusion rate ${ }^{9,10}$. An aggressive surgery by means of $360^{\circ}$ fusion, although linked with higher fusion rates, is not always associated with a favorable clinical outcome $^{9}$. Several clinical problems have been attributed to intraoperative damage of the posterior muscle groups. Numerous studies have shown that lumbar surgery through a posterior approach results in erector spinae muscle changes, demonstrated through clinical studies measuring extensor strength ${ }^{11,12}$, histologic studies ${ }^{11,13,14,15,16,17}$ and postoperative imaging studies by computed tomography $(\mathrm{CT})^{11}$ or magnetic resonance imaging (MRI). ${ }^{18}, 19$ In addition erector spinae are detached from the paravertebral gutters then held laterally by self-retaining retractors during posterior lumbar surgery. Studies by Kawaguchi et al. suggest that pressure caused by self-retaining retractors leads to lesions of the erector spinae ${ }^{13}$. Results from biomechanical and clinical studies indicate that an anterior only approach utilizing an interbody spacer and anterior plate seem to provide stability comparable to that of a $360^{\circ}$ (interbody + pedicle screw fixation) and less postoperative morbidity. ${ }^{20}$ However, the anterior only standard of care is the use of an interbody device with an anterior plate which protrudes anteriorly from the vertebral bodies creating a raised profile which interferes with the great vessels which are also anterior and adjacent to the lumbar vertebral bodies. The profile of current plates for anterior fusion is lower than that of earlier designs, but they are still bulky and might lead to postoperative complications. The insertion of these plates is a time-consuming surgical procedure which requires wider surgical exposure, more tissue dissection, anterior muscle disruption, and higher post-op morbidity. During this procedure some anatomical structures on the anterior aspect of the lumbar spine, such as the great vessels, are endangered. Other disadvantages include screw migration with possible soft tissue damage, increased of risk of adjacent level ossification and difficulty in stacking plates for adjacent level surgery. As a further improvement of this anterior only concept, combination or integrated interbody spacers for zero- or low profile segmental stabilization have been developed to perform the role of the separate spacer and plate. The proposed benefit of these integrated devices is that they provide sufficient stabilization to promote biologic fusion while avoiding posterior soft tissue morbidity during the primary procedure. In addition, the concern for adjacent level ossification is less, and in cases of adjacent level disease, the integrated interbody device can be placed without interfering 
with the previously operated segment nor requiring removal of the previously placed anterior plate. An additional benefit of these integrated devices is that they fit completely inside the disc space therefore limiting the exposure of the anterior spine column and potentially reduce complications such as vascular injury ${ }^{21,22,23,24}$. The objective of this study was to determine if an Integrated Interbody Fusion Device (PILLAR SA, Orthofix, Lewisville, TX) Figure 1A can stabilize single motion segments as effectively as an anterior interbody spacer (PILLAR AL, Orthofix, Lewisville, TX) Figure 1B + posterior instrumentation (pedicle screw construct) i.e. a $360^{\circ}$ fusion construct. The following hypotheses were tested: (1) An Integrated Lumbar Interbody Fusion Device (PILLAR SA) will significantly reduce motion at the implanted level, relative to intact; (2) The PILLAR SA device will function biomechanically similar to a traditional anterior interbody spacer (PILLAR AL) plus posterior instrumentation $\left(360^{\circ}\right.$ fusion construct). 

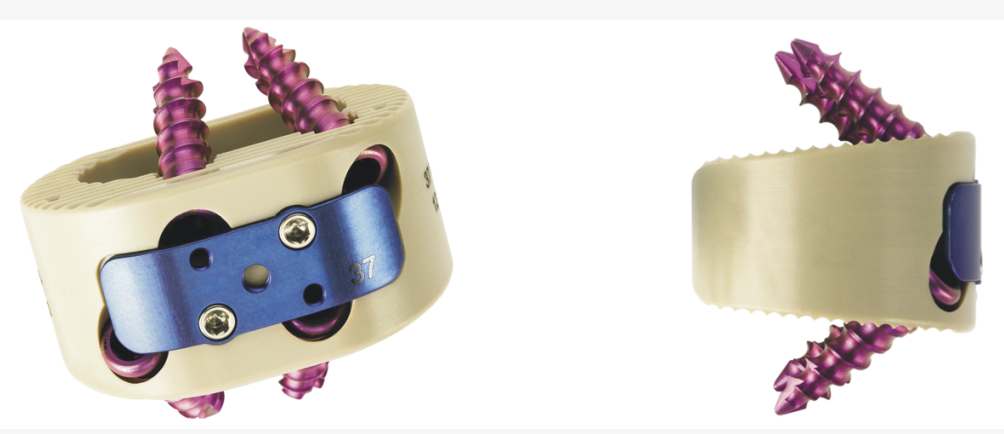

Fig. 1A. Integrated interbody fusion device PILLAR SA, Orthofix, Lewisville, TX.

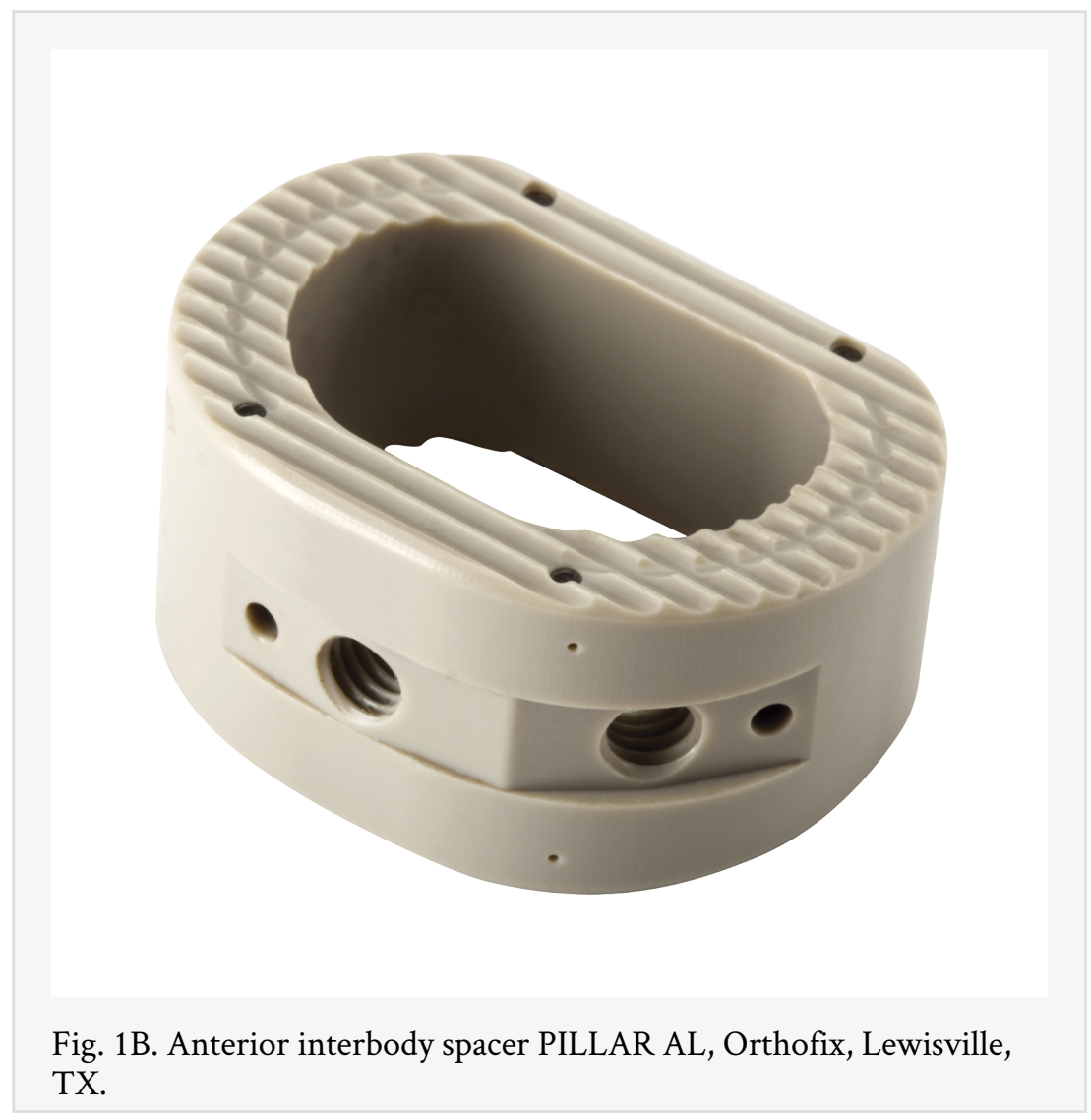

\section{Materials and Methods}

\section{Specimens and Experimental Setup}

Eight fresh frozen human cadaveric spine specimens (L1-S1) were used for this study (age: $43.9 \pm 4.3$ years). Radiographic screening was performed to exclude specimens with fractures, metastatic disease, bridging osteophytes, osteoporosis, previous spine surgeries or other conditions that could significantly affect the biomechanics of the spine. Bone mineral density (BMD) of each specimen was determined using a peripheral Quantitative Computed Tomography (pQCT) (Norland Medical Systems, Inc). A rectangular area 10 by $10 \mathrm{~mm}$ in the middle of the T12 vertebral body was investigated with an exposure dose 
of $200 \mathrm{~mA}$ and $120 \mathrm{KVp}$. Based on the criteria proposed by WHO, specimens with normal BMD (BMD $>150 \mathrm{mg} / \mathrm{cm}^{3}$ ) were used for the study. ${ }^{25}$ Specimen demographics and pQCT values are presented in Table 1. The specimens were thawed and stripped of the paraspinal musculature while preserving the discs, facet joints, and osteoligamentous structures. The specimens were wrapped in saline soaked towels to prevent dehydration of the soft tissues. All tests were performed at room temperature. The specimens were fixed to the apparatus at the caudal end and free to move in any plane at the cephalad end Figure 2. A moment was applied by controlling the flow of water into bags attached to loading arms fixed to the L1 vertebra. The apparatus allows continuous cycling of the specimen between specified maximum moment endpoints in flexion, extension, lateral bending, and axial rotation. The load-displacement data was collected until two consecutive reproducible load-displacement loops were obtained. The angular motion of the L1 to S1 vertebrae were measured using an optoelectronic motion measurement system (Model 3020, Optotrak, Northern Digital, Waterloo, Ontario). In addition, bi-axial angle sensors (Model 902-45, Applied Geomechanics, Santa Cruz, CA) were mounted on each vertebra to allow real-time feedback for the optimization of the preload path. A sixcomponent load cell (Model MC3A-6-1000, AMTI Multi-component transducers, AMTI Inc., Newton, MA) was placed under the specimen to measure the applied compressive preload and moments. Fluoroscopic imaging (GE OEC 9800 Plus digital fluoroscopy machine) was used in the neutral, flexed and extended postures during the kinematic testing and during surgical implantations to ensure correct implant placement.

Table 1. Specimen Demographics

\begin{tabular}{|l|l|l|l|l|}
\hline Specimen & Age (years) & Sex & pQCT $\left(\mathbf{m g} / \mathbf{c m}^{3}\right)$ \\
\hline 1 & 40 & M & 215 \\
\hline 2 & 38 & M & 210 \\
\hline 3 & 42 & M & 150 \\
\hline 4 & 45 & F & 211 \\
\hline 5 & 41 & F & 190 \\
\hline 6 & 50 & M & 205 \\
\hline 7 & 48 & M & 182 \\
\hline 8 & 47 & F & 189 \\
\hline Mean & 43.9 & $\mathbf{5 M} / \mathbf{3 F}$ & $\mathbf{1 9 4}$ \\
\hline SD & 4.3 & & 21.5 \\
\hline
\end{tabular}




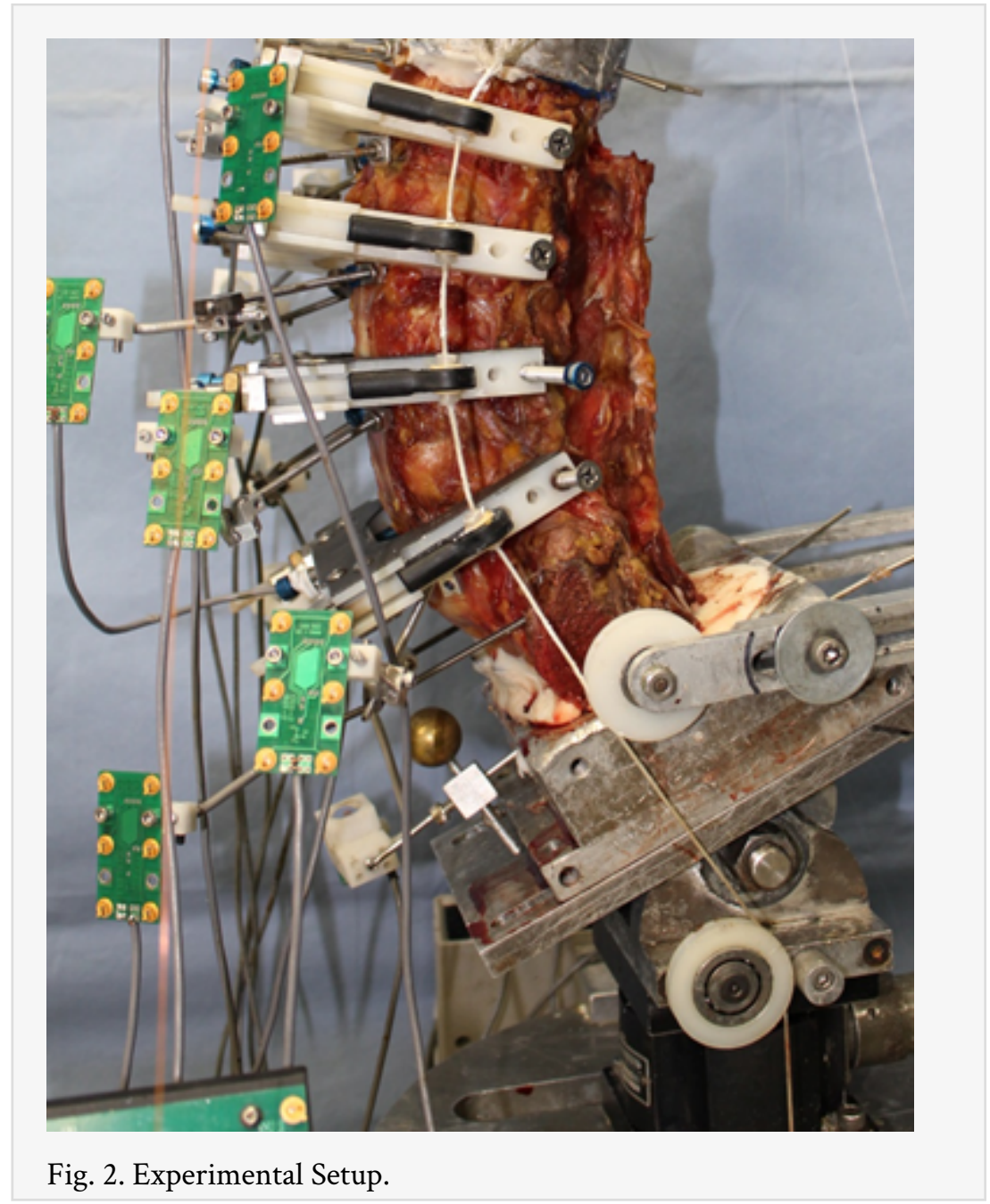

\section{Experimental Protocol}

Each specimen's range of motion was tested in flexion-extension, lateral bending, and axial rotation Figure 3 under the following sequential conditions:

1. Intact spine;

2. Nucleotomy at L4-L5 (to simulate mechanical instability of disc degeneration);

3. PILLAR SA at L4-L5 (with intervertebral screws);

4. PILLAR SA + Pedicle Screws and rods at L4-L5 (FIREBIRD);

5. PILLAR AL + Pedicle Screws and rods at L4-L5 (FIREBIRD). 



Fig. 3. Experimental Protocol.

Each specimen was tested in flexion $(8 \mathrm{Nm})$ and extension $(6 \mathrm{Nm})$ without preload $(0 \mathrm{~N})$ and under $400 \mathrm{~N}$ of follower preload. Each specimen was also tested in lateral bending $( \pm 6$ $\mathrm{Nm})$ and axial rotation $( \pm 5 \mathrm{Nm})$ without preload. ${ }^{26,27,28,29}$

\section{Data Analysis}

The applied moment versus angular motion data were used to calculate the range of motion values in all three modes. Range of motion values were analyzed using repeated measures analysis of variance with a post-hoc Bonferroni correction for multiple comparisons. The following comparisons were made:

1. 1 vs. 3 Intact vs. Integrated Cage

2. 3 vs. 4 Integrated Cage + Pedicle Screws $\&$ Rods vs. Integrated Cage

3. 3 vs. 5 Integrated Cage vs. 360 fusion with Spacer

These comparisons were done separately for flexion-extension, lateral bending, and axial rotation, since no comparisons across load-types were intended in the study design. The statistical data analyses were performed with use of the Systat 10.2 software package (Systat Software, Richmond, CA). 


\section{Results}

Representative applied moment versus angular displacement graphs (Figure 4, Figure 5, Figure 6, Figure 7) depict the classic sigmoidal behavior of the L4-L5 motion segments in the intact condition, followed by nucleotomy, and stabilization using each of three constructs tested in this study. 


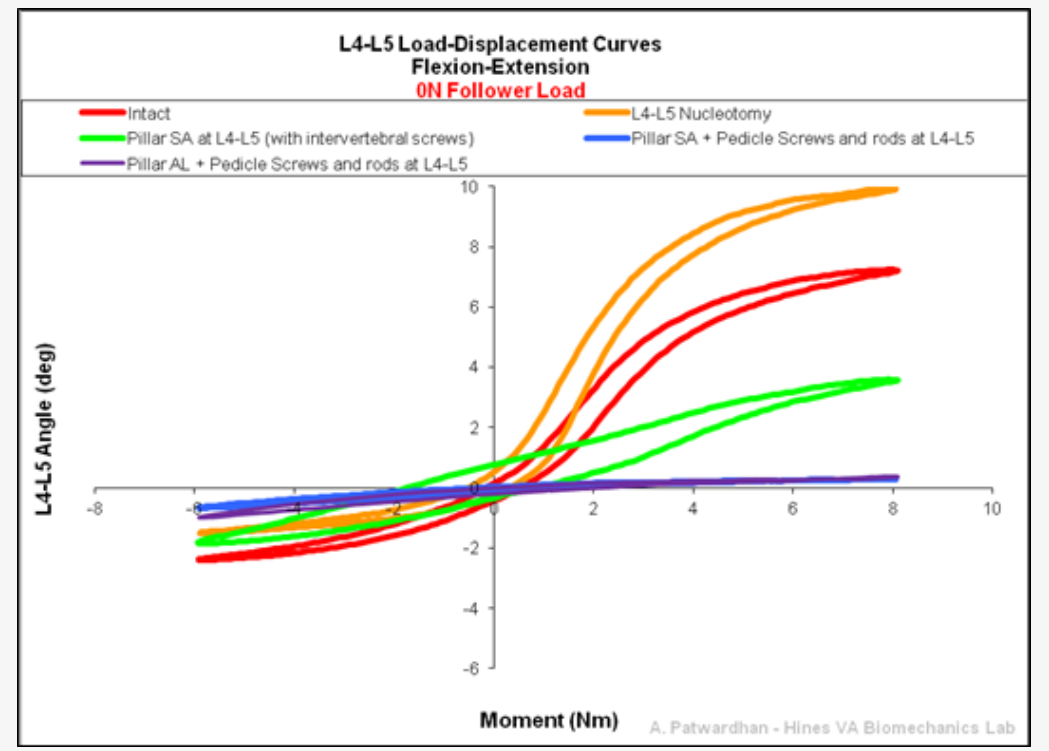

Fig. 4. Representative L4-L5 Load-Displacement Curves in flexionextension $0 \mathrm{~N}$ of preload.



Fig. 5. Representative L4-L5 Load-Displacement Curves in flexionextension $400 \mathrm{~N}$ of follower preload. 


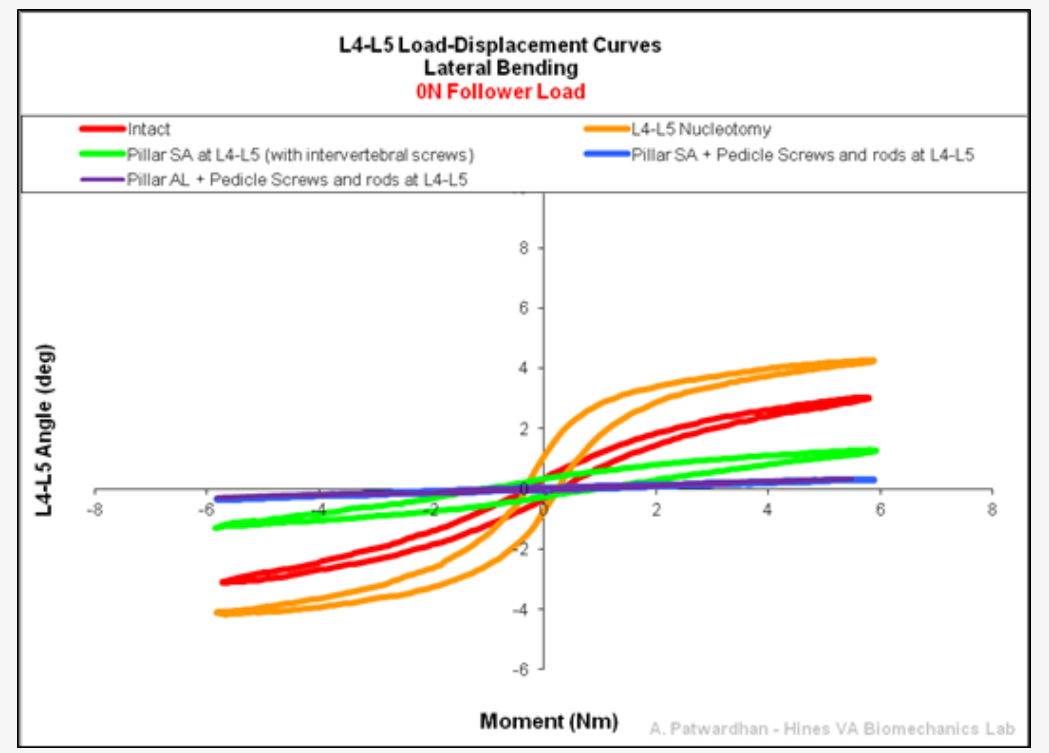

Fig. 6. Representative L4-L5 Load-Displacement Curves in lateral bending $0 \mathrm{~N}$.

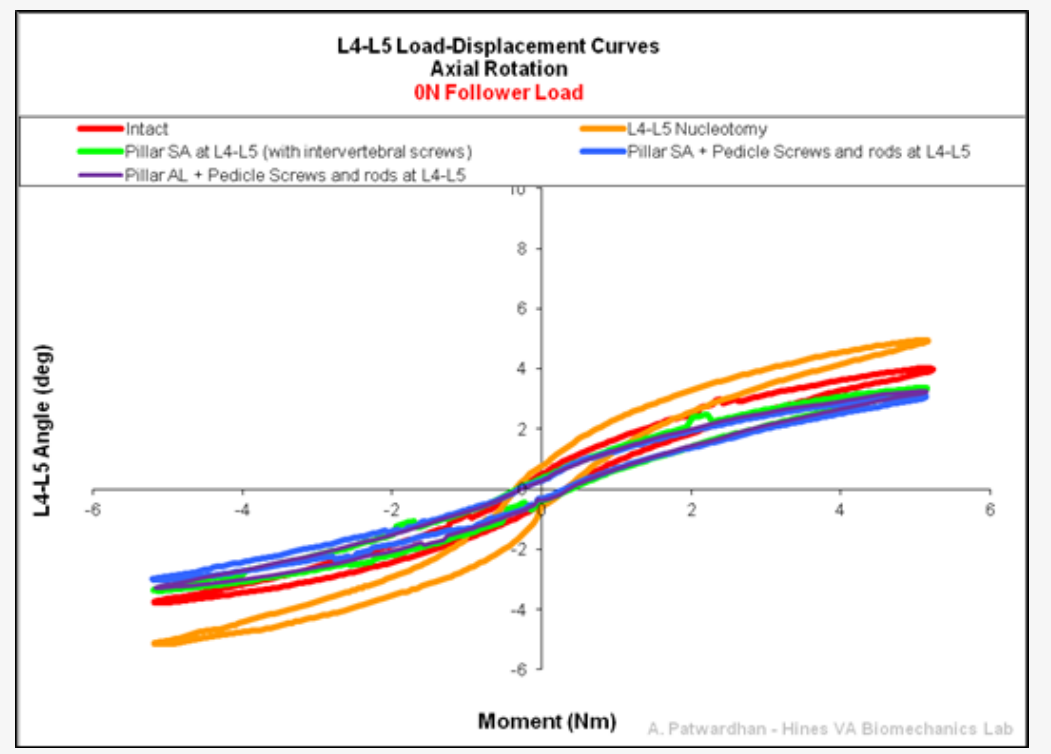

Fig. 7. Representative L4-L5 Load-Displacement Curves in axial rotation.

\section{Range of Motion}

\section{Flexion-Extension}

In the absence of a compressive preload, the intact spine had a total angular motion of $9.0 \pm 2.3$ degrees in flexion-extension corresponding to the moments used in this study (0-8Nm flexion, $0-6 \mathrm{Nm}$ extension) Figure 8 . The motion increased to $11.8 \pm 2.7$ degrees after nucleotomy ( $\mathrm{p}<0.01$, compared to intact), then decreased to $5.6 \pm 3.2$ degrees after implantation of the integrated lumbar cage (PILLAR SA), a reduction of $39.5 \pm 24.9 \%$ ( $<<$ 0.01 , compared to intact). The addition of bilateral pedicle screws and rods to the 
integrated cage construct reduced the motion further, to $1.3 \pm 0.9$ degrees $(\mathrm{p}<0.01$, compared to intact). The construct involving an interbody spacer (PILLAR AL) with supplemental bilateral pedicle screws and rods resulted in $1.7 \pm 1.2$ degrees of angular motion at the L4-L5 segment, a reduction of $81.9 \pm 10.2 \%$ ( $\mathrm{p}<0.01$, compared to intact). Application of a physiologic compressive preload of $400 \mathrm{~N}$ caused a further decrease in motion of all fusion constructs(Figure 8 ). The angular motion of the construct utilizing the PILLAR SA implant was reduced to $3.4 \pm 1.7$ degrees, a reduction of $64.5 \pm 12.7 \%$ from intact ( $\mathrm{p}<0.01$, compared to $0 \mathrm{~N}$ preload). This is a significant improvement in the performance of the integrated cage due to the addition of physiologic compressive preload (64.5\% vs. $39.5 \%$ reduction from intact motion). The $360^{\circ}$ fusion yielded motion of $1.1 \pm 0.5$ degrees in flexion-extension, which was significantly less than the motion in the construct using the integrated fusion device $(\mathrm{p}<0.05)$. When the flexion and extension modes were analyzed separately, the integrated cage device, in the absence of a compressive preload, reduced motion in flexion ( $\mathrm{p}<0.01$, compared to intact) but not in extension ( $p>0.9$, compared to intact) (Figure $9 \&$ Figure 10). With the addition of a 400 $\mathrm{N}$ compressive preload, the motion of the integrated cage construct further reduced in flexion and the motion in extension became significantly smaller than intact $(p<0.05)$. 


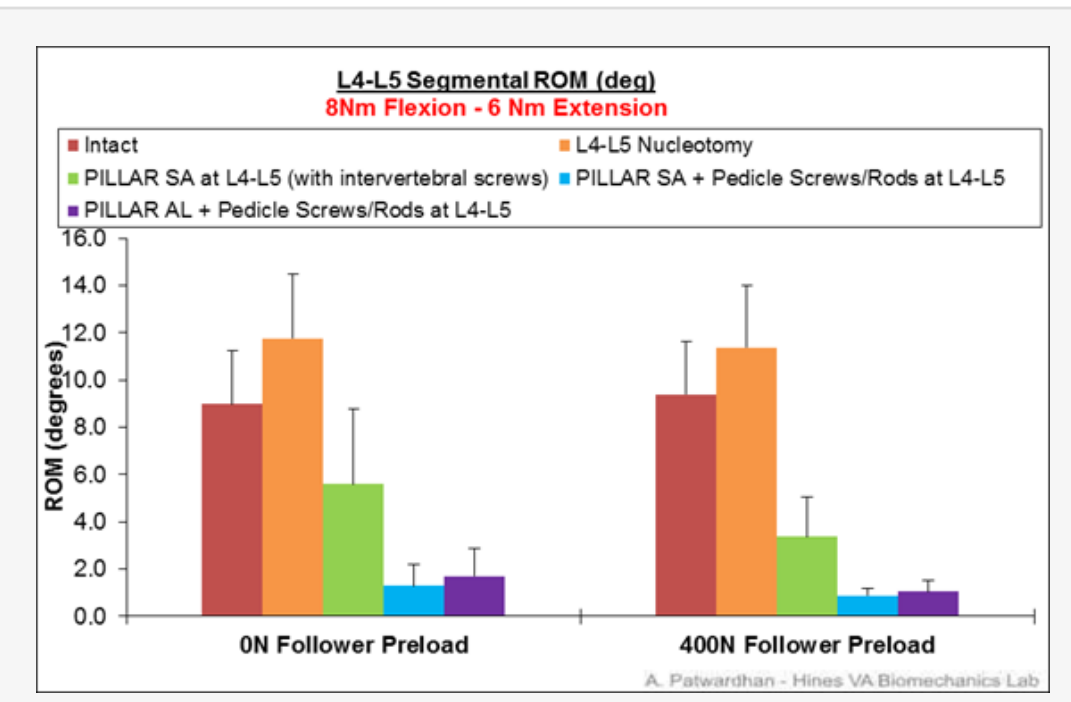

Fig. 8. L4-L5 segmental flexion-extension range of motion in degrees.

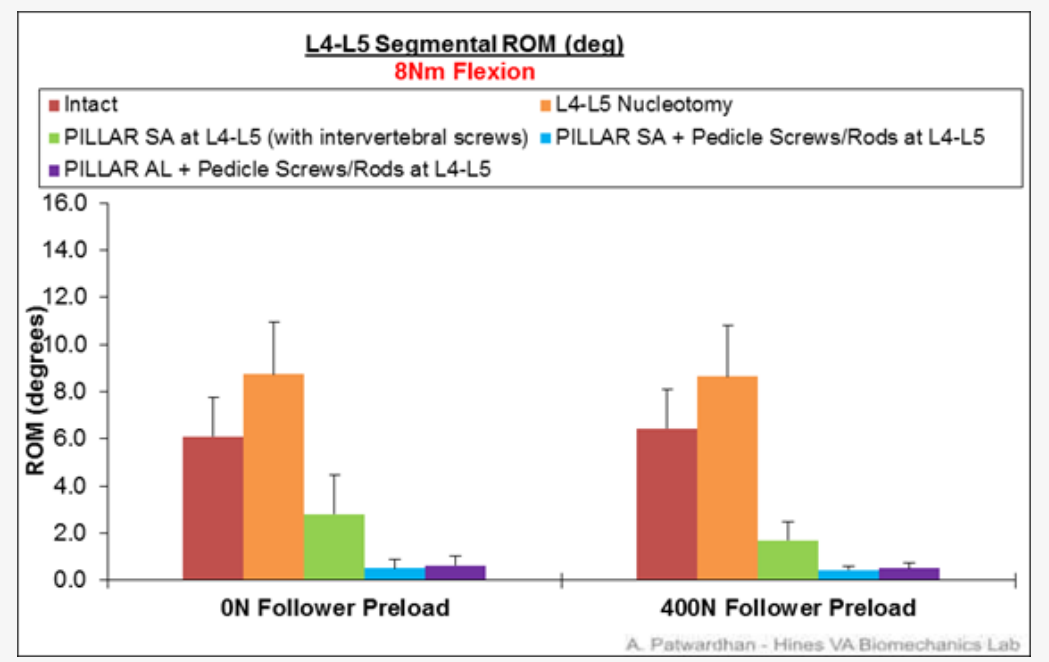

Fig. 9. L4-L5 segmental flexion range of motion in degrees. 


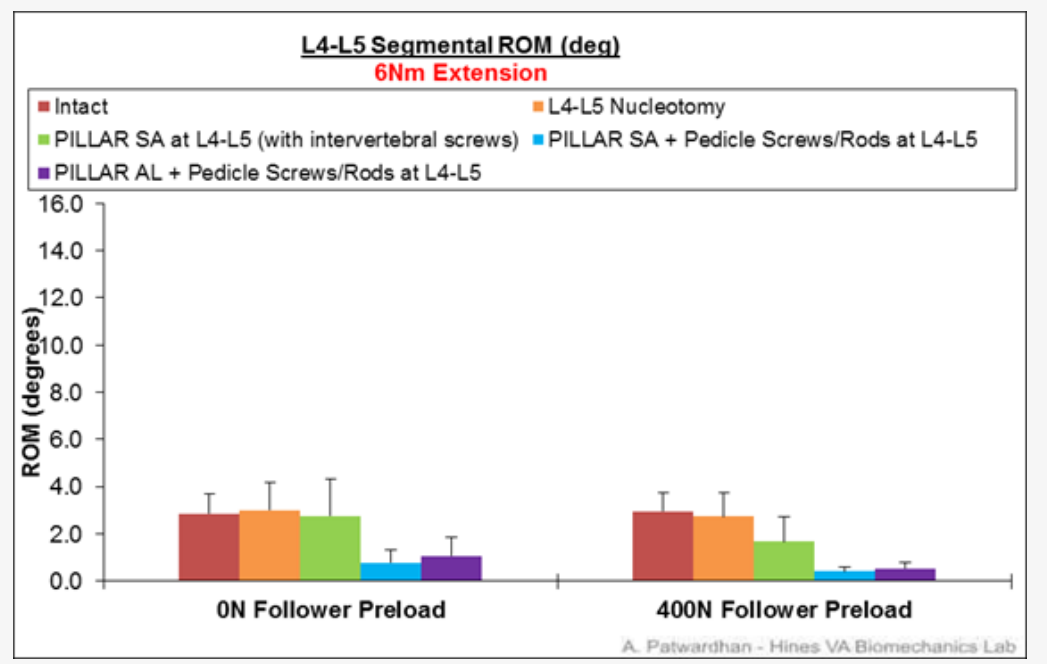

Fig. 10. L4-L5 segmental extension range of motion in degrees.

\section{Lateral Bending and Axial Rotation}

The intact spine had a total angular motion of $8.4 \pm 1.8$ degrees in (right + left) lateral bending corresponding to the moments of $\pm 6 \mathrm{Nm}$ Figure 11 . The motion increased to $10.4 \pm 3.0$ degrees after nucleotomy ( $\mathrm{p}<0.05$, compared to intact), then decreased to $2.9 \pm 1.5$ degrees after implantation of the integrated lumbar cage (PILLAR SA) $(\mathrm{p}<0.01$, compared to intact). The addition of bilateral pedicle screws and rods to the integrated cage construct reduced the motion further, to $0.8 \pm 0.5$ degrees $(\mathrm{p}<0.01$, compared to intact). The construct involving an interbody spacer (PILLAR AL) with supplemental bilateral pedicle screws and rods resulted in $1.0 \pm 0.8$ degrees of angular motion at the L4-L5 segment ( $\mathrm{p}<0.01$, compared to intact). This $360^{\circ}$ fusion construct yielded significantly less motion than the construct using the integrated fusion device $(p<0.05)$. Under moments of $\pm 5 \mathrm{Nm}$ in axial rotation, the angular motion at L4-L5 was reduced from $2.4 \pm 1.2$ degrees in intact to $0.8 \pm 0.5$ degrees after implantation of the PILLAR SA ( $p<$ 0.01 , compared to intact). The addition of bilateral pedicle screws and rods reduced the motion further, to $0.5 \pm 0.4$ degrees ( $\mathrm{p}<0.01$, compared to intact). The $360^{\circ}$ fusion yielded motion of $0.7 \pm 0.4$ degrees, which was statistically equivalent to the motion in the construct using the integrated fusion device $(\mathrm{p}>0.05)$. 


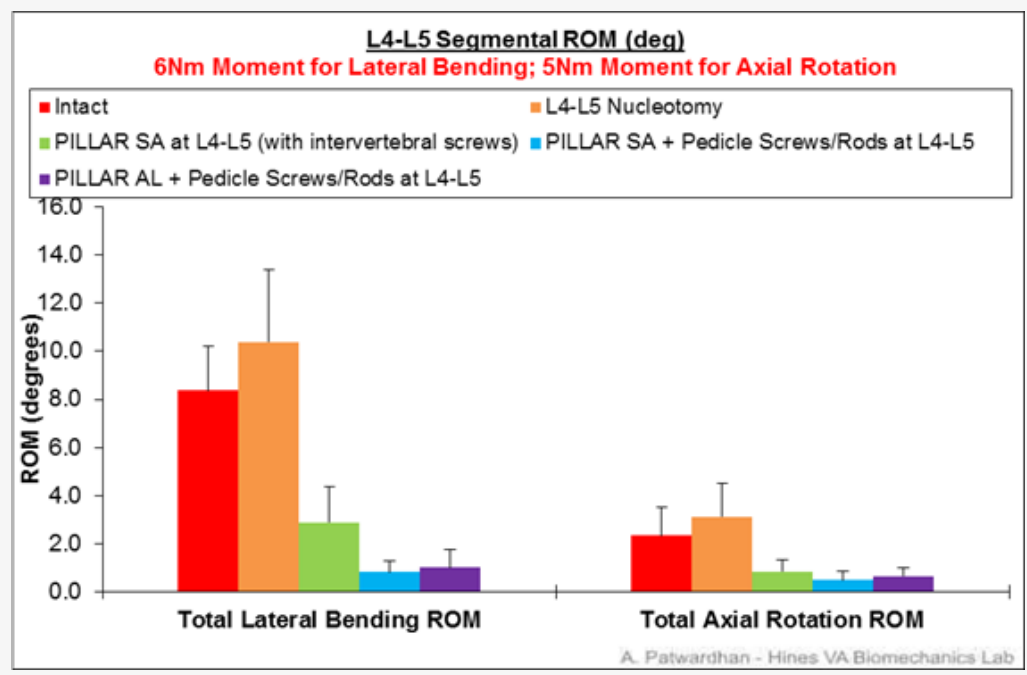

Fig. 11. L4-L5 segmental range of motion in lateral bending and axial rotation.

\section{Discussion}

This study was designed to evaluate and compare the biomechanical ability of an integrated lumbar interbody fusion device (PILLAR SA, Orthofix, Lewisville, TX) to a traditional anterior interbody spacer (PILLAR AL, Orthofix, Lewisville, TX) supplemented with posterior instrumentation (FIREBIRD, Orthofix, Lewisville, TX). As a further improvement of anterior only surgical fusion approach and as an alternative to the traditional cage and anterior plate construct to alleviate numerous complications, combination or integrated interbody spacers for zero- or low profile segmental stabilization have been developed to perform the role of the separate spacer and plate. Based on the clinical outcomes of current fusion options, complexity of certain surgical procedures $\left(360^{\circ}\right.$ fusion, transarticular facet screws, etc.), excessive soft tissue dissection during anterior plating option, and technical difficulties in plate insertion during surgical procedures for adjacent segment degeneration cases led to the necessity for lumbar (as well as cervical) anterior cage devices with integrated screws. There are several publications reporting the biomechanical performance of such devices as a stand-alone construct or in conjunction with "traditional" fusion options. Kuzhupilly et al. have previously evaluated the stiffness of a femoral ring allograft (FRA) with and without integrated crossed anterior screws under $\pm 4 \mathrm{Nm}$ in flexion-extension and lateral bending and $\pm 2.5 \mathrm{Nm}$ in axial rotation with a compressive preload of $100-150 \mathrm{~N} .{ }^{30}$ The integrated FRA plus screws was surprisingly significantly less stiff than intact in flexion-extension and about the same as intact in lateral bending. The integrated screws significantly improved the stability of the femoral ring allograft spacers in extension with a trend toward increasing of stiffness in torsion. Cain et al. compared the stand-alone anterior integrated lumbar cage and "traditional" fusion constructs (cage with transarticular facet screws or pedicle screws) under $\pm 6 \mathrm{Nm}$ with a compressive preload of $50 \mathrm{~N}^{4}$. The integrated cage reduced the motion to 6.5 degrees in flexion-extension, 3.3 degrees in lateral bending, and 1.1 degrees in axial rotation. The construct using an interbody spacer and bilateral pedicle screws had uncharacteristically large residual motions of 5.9 degrees in flexion-extension, 3.2 degrees in lateral bending and 1.6 degrees in rotation. Schleicher 
et al. compared two integrated cage implants - PEEK cage with integrated anterior titanium plate with four diverging locking screws and stand-alone anterior cage with four integrated screws - under $\pm 6 \mathrm{Nm}$ without a compressive preload ${ }^{31}$. Results of this study showed a significant stabilizing effect for both implants in all loading directions; the residual motions were about 2 degrees in flexion-extension and lateral bending and about 1 degree in axial rotation. It should be noted, however, that the native segments seemed to have smaller than normal ranges of motion; only 5.2 degrees in flexion-extension, 2.6 degrees in lateral bending and 2.2 degrees in axial rotation. Beaubien et al. evaluated a stand-alone cage with integrated screws under a moment of $\pm 7.5 \mathrm{Nm}$ with $100 \mathrm{~N}$ compressive preload $^{3}$. The motion after implantation of the integrated cage was 6.1 degrees in flexion-extension, 5.1 in lateral bending, and 1.8 in axial rotation. The construct with bone graft and pedicle screws was the most stable, with motions of less than 2 degrees in all three modes. Kornblum et al. evaluated the biomechanical stability of ALIF constructs by comparing those using a stand-alone integrated cage device with traditional ALIF supplemental fixation construct under $\pm 7.5 \mathrm{Nm}$ without a compressive preload $^{32}$. These authors did not report the residual motion in degrees; instead they report the results as percent of intact motion. The integrated cage with 3 or 4 screws had residual motions of about $40 \%$ of intact in flexion-extension, about $30 \%$ in lateral bending and between $45 \%$ and $55 \%$ of intact in axial rotation. The construct with cage and bilateral pedicle screws was more rigid, with residual motions of about $15 \%$ of intact in flexionextension and lateral bending, and about $35 \%$ on intact in axial rotation. In our study we reported biomechanical results using a follower preload of $400 \mathrm{~N}$ as well as no preload option. The application of follower preload represents an attempt at simulating the "muscle involvement" and mimicking the in vivo scenario, while testing without preload represents a worst-case scenario, but gives a chance to compare our results with other investigators' published studies, where follower load testing was not used. Limitations of this current study as well as for all research studies using cadaveric tissue remain the same: inability to simulate biological fusion and show only acute tissue response and represent the immediate postoperative period. The PILLAR SA device differs from other lumbar integrated interbody devices in that it uses a 4-screw design with medial-oriented screw holes. In addition, its ovoid shape parallels the apophyseal ring of the vertebral body, while providing a wide central opening to hold a larger amount of potential graft material. Lastly, it has a cover plate that stops the possibility of screw back-out while maintaining a nearly zero profile. The PILLAR SA implantation resulted in motions of about $3^{\circ}$ under physiologic loads in all modes of motion but was not as motion restricting as the traditional $360^{\circ}$ construct using interbody spacer and bilateral pedicle screws. The residual segmental motions compare very favorably with published biomechanical studies of other lumbar interbody integrated fusion devices ${ }^{3,4}$. In addition, motions of about $3^{\circ}$ in FE are considered to be sufficient to promote solid biological spinal fusion $33,34,35,36$.

\section{Conclusions}

The PILLAR SA implantation resulted in motions of less than $3^{\circ}$ in all modes of motion but was not as motion restricting as the traditional $360^{\circ}$ using bilateral pedicle screws. The residual segmental motions compare very favorably with published biomechanical studies of other lumbar interbody integrated fusion devices. A physiologic compressive preload due to the action of the musculature in vivo acts to stabilize the interface between the interbody device and vertebral endplates, and therefore should be incorporated into 
biomechanical test setup for interbody device assessment. The clinical impact of our results is additional information for clinicians who might previously have been apprehensive with respect to performing a lumbar fusion using a stand-alone device. Normally this concern might result in posterior instrumentation being added to the anterior device to ensure stability of the fusion site. However, performing a circumferential fusion adds additional surgical complications due to a secondary surgical site in addition to extending the duration of the entire surgery. The presented results indicate that although the PILLAR SA alone is not as motion-restrictive as the 360 fusion, the motion of the fusion segment is still restricted to a degree that will enable fusion to occur as compared to what is seen in the literature. Additional future studies should be randomized, prospective clinical trials to further support the evidence presented in this paper.

\section{References}

1. Beaubien BP, Mehbod AA, Kallemeier PM, et al. Posterior augmentation of an anterior lumbar interbody fusion: minimally invasive fixation versus pedicle screws in vitro. Spine 2004;29:E406-12.

2. Beaubien BP, Derincek A, Lew WD, Wood KB. In vitro, biomechanical comparison of an anterior lumbar interbody fusion with an anteriorly placed, low-profile lumbar plate and posteriorly placed pedicle screws or translaminar screws. Spine 2005;30:1846-51.

3. Beaubien BP, Freeman AL, Turner JL, et al. Evaluation of a lumbar intervertebral spacer with integrated screws as a stand-alone fixation device. J Spinal Disord Tech 2010;23:351-8.

4. Cain CM, Schleicher P, Gerlach R, et al. A new stand-alone anterior lumbar interbody fusion device: biomechanical comparison with established fixation techniques. Spine 2005;30:2631-6.

5. Gerber M, Crawford NR, Chamberlain RH, et al. Biomechanical assessment of anterior lumbar interbody fusion with an anterior lumbosacral fixation screw-plate: comparison to stand-alone anterior lumbar interbody fusion and anterior lumbar interbody fusion with pedicle screws in an unstable human cadaver model. Spine 2006;31:762-8.

6. Karahalios DG, Kaibara T, Porter RW, et al. Biomechanics of a lumbar interspinous anchor with anterior lumbar interbody fusion. J Neurosurg Spine 2010;12:372-80.

7. Tzermiadianos MN, Mekhail A, Voronov LI, et al. Enhancing the stability of anterior lumbar interbody fusion: a biomechanical comparison of anterior plate versus posterior transpedicular instrumentation. Spine 2008;33:E38-43.

8. Wang JC, Spenciner D, Robinson JC. SPIRE spinous process stabilization plate: biomechanical evaluation of a novel technology. Invited submission from the Joint Section Meeting on Disorders of the Spine and Peripheral Nerves, March 2005. J Neurosurg Spine 2006;4:160-4.

9. Fritzell P, Hägg O, Wessberg P, Nordwall A; Swedish Lumbar Spine Study Group. Chronic low back pain and fusion: a comparison of three surgical techniques: a prospective multicenter randomized study from the Swedish lumbar spine study group. Spine (Phila Pa 1976). 2002 Jun 1;27(11):1131-41.

10. Gertzbein SD, Betz R, Clements D, Errico T, Hammerberg K, Robbins S, Shepherd E, Weber A, Kerina M, Albin J, Wolk D, Ensor K. Semirigid instrumentation in the 
management of lumbar spinal conditions combined with circumferential fusion. A multicenter study. Spine (Phila Pa 1976). 1996 Aug 15;21(16):1918-25.

11. Gejo R, Matsui H, Kawaguchi $Y$, et al. Serial changes in trunk muscle performance after posterior lumbar surgery. Spine 1999;24:1023-8.

12. Mayer TG, Vanharanta H, Gatchel RJ, et al. Comparison of CT scan muscle measurements and isokinetic trunk strength in postoperative patients. Spine 1989;14:33-6.

13. Kawaguchi $\mathrm{Y}$, Matsui $\mathrm{H}$, Tsuji $\mathrm{H}$. Back muscle injury after posterior lumbar spine surgery: a histologic and enzymatic analysis. Spine 1996;21:941-4.

14. Kawaguchi $Y$, Matsui $H$, Tsuji H. Back muscle injury after posterior lumbar spine surgery: Part 1. Histologic and histochemical analysis in rats. Spine 1994;19:2590-7.

15. Kawaguchi $\mathrm{Y}$, Matsui $\mathrm{H}$, Tsuji $\mathrm{H}$. Back muscle injury after posterior lumbar spine surgery: Part 2. Histologic and histochemical analyses in humans. Spine 1994;19:2598-602.

16. Taylor H, McGregor AH, Medhi-Zadeh S, et al. The impact of self-retaining retractors on the paraspinal muscles during posterior spinal surgery. Spine 2002;27:2758-62.

17. Weber BR, Grob D, Dvorak J, et al. Posterior surgical approach to the lumbar spine and its effect on the multifidus muscle. Spine 1997;22:1765-72.

18. Gejo R, Kawaguchi Y, Kondoh T, et al. Magnetic resonance imaging and histologic evidence of postoperative back muscle injury in rats. Spine 2000;25:941-6.

19. Kim DY, Lee SH, Chung SK, et al. Comparison of multifidus muscle atrophy and trunk extension muscle strength: percutaneous versus open pedicle screw fixation. Spine 2005;30:123-9.

20. Memtsoudis SG, Vougioukas VI, Ma Y, et al. Perioperative morbidity and mortality after anterior, posterior and anterior posterior spine fusion surgery. Spine (Phila $\mathrm{P}$ 1976) 2011 Oct 15;36(22):1867-77.

21. Baker JK, Reardon PR, Reardon MJ, Heggeness MH. Vascular injury in anterior lumbar surgery. Spine 1993;18:2227-30.

22. Brau SA, Delamarter RB, Schiffman ML, et al. Vascular injury during anterior lumbar surgery. Spine J 2004;4:409-12.

23. Fantini GA, Pappou IP, Girardi FP, et al. Major vascular injury during anterior lumbar spinal surgery: incidence, risk factors, and management. Spine 2007;32:2751-8.

24. Wood KB, Devine J, Fischer D, et al. Vascular injury in elective anterior lumbosacral surgery. Spine 2010;35:S66-75.

25. Assessment of fracture risk and its application to screening for postmenopausal osteoporosis. Report of a WHO Study Group. World Health Organ Tech Rep Ser 843:1-129, 1994

26. Patwardhan AG, Havey RM, Meade KP, Lee B, Dunlap B: A Follower Load Increases the Load Carrying Capacity of the Lumbar Spine in Compression. Spine, 24(10):1003-9, 1999.

27. Patwardhan AG, Carandang G, Ghanayem A, Havey R, et al. Compressive preload improves the stability of the anterior lumbar interbody fusion (ALIF) cage construct. J Bone Joint Surg (Am), 2003 Sep;85-A(9):1749-56.

28. Phillips FM, Cunningham B, Carandang G, Ghanayem AJ, Voronov LI, Havey RM, Patwardhan AG. Effect of Supplemental Translaminar Facet Screw Fixation on the 
Stability of Stand-Alone ALIF Cages Under Physiologic Loads. Spine, 2004;29:1731-6.

29. Tzermiadianos MN, Mekhail A, Voronov LI, Zook J, Havey RM, Renner SM, Carandang G, Abjornson C, Patwardhan AG. Enhancing the stability of anterior lumbar interbody fusion: a biomechanical comparison of anterior plate versus posterior transpedicular instrumentation. Spine. 2008 Jan 15;33(2):E38-43.

30. Kuzhupilly RR, Lieberman IH, McLain RF, Valdevit A, Kambic H, Richmond BJ. In vitro stability of FRA spacers with integrated crossed screws for anterior lumbar interbody fusion. Spine (Phila Pa 1976). 2002 May 1;27(9):923-8

31. Schleicher P, Gerlach R, Schär B, Cain CM, Achatz W, Pflugmacher R, Haas NP, Kandziora F. Biomechanical comparison of two different concepts for stand alone anterior lumbar interbody fusion. Eur Spine J. 2008 Dec;17(12):1757-65.

32. Kornblum MB, Turner AW, Cornwall GB, Zatushevsky MA, Phillips FM. Biomechanical evaluation of stand-alone lumbar polyether-ether-ketone interbody cage with integrated screws. Spine J. 2013 Jan;13(1):77-84.

33. Bono CM, Khandha A, Vadapalli S, Holekamp S, Goel VK, Garfin SR. Residual sagittal motion after lumbar fusion: a finite element analysis with implications on radiographic flexion-extension criteria. Spine (Phila Pa 1976). 2007 Feb 15;32(4):417-22.

34. Bono CM, Bawa M, White KK, Mahar A, Vives M, Kauffman C, Garfin SR. Residual motion on flexion-extension radiographs after simulated lumbar arthrodesis in human cadavers. J Spinal Disord Tech. 2008 Jul;21(5):364-71.

35. Kuslich SD, Danielson G, Dowdle JD, Sherman J, Fredrickson B, Yuan H, Griffith SL. Four-year follow-up results of lumbar spine arthrodesis using the Bagby and Kuslich lumbar fusion cage. Spine (Phila Pa 1976). 2000 Oct 15;25(20):2656-62.

36. Kuslich SD, Ulstrom CL, Griffith SL, Ahern JW, Dowdle JD. The Bagby and Kuslich method of lumbar interbody fusion. History, techniques, and 2-year followup results of a United States prospective, multicenter trial. Spine (Phila Pa 1976). 1998 Jun 1;23(11):1267-78.

\section{Corresponding Author}

Avinash G. Patwardhan, PhD, Department of Orthopaedic Surgery and Rehabilitation, Loyola University Chicago, 2160 S. First Avenue, Maywood, IL 60153, USA. Phone: (708) 202-5804; Fax: (708) 202-7938; E-Mail: apatwar@lumc.edu

\section{Acknowledgments}

Supported by the US Department of Veterans Affairs, Washington, DC, and Orthofix, Lewisville, Texas.

\section{Disclosures}

Erik Waldorff is an employee of Orthofix, Inc. Michael R. Zindrick acts as a consultant to OrthoFix and receives royalties from Orthofix for a device unrelated to this study.

Copyright (C) 2014 ISASS - International Society for the Advancement of Spine Surgery. To see more or order reprints or permissions, see http://ijssurgery.com. 